Western University Scholarship@Western

1978

\title{
Unemployment and Inflation: Facts, Theories, Puzzles and Policies
}

Michael Parkin

Follow this and additional works at: https://ir.lib.uwo.ca/economicsresrpt

Part of the Economics Commons

Citation of this paper:

Parkin, Michael. "Unemployment and Inflation: Facts, Theories, Puzzles and Policies." Department of Economics Research Reports, 7831. London, ON: Department of Economics, University of Western Ontario (1978). 
UNEMPLOYMENT AND INFLATION:

FACTS, THEORIES, PUZZLES AND POLICIES

by

Michael Parkin

October, 1978

Department of Economics Libray

APR $211983^{\circ}$

University of Westem Ontario

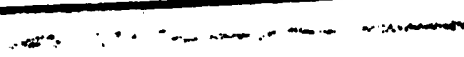


UNEMPLOYMENT AND INFLATION:

FACTS, THEORIES, PUZZLES AND POLICIES

by

\author{
Michael Parkin \\ Department of Economics \\ University of Western Ontario \\ Iondon, Ontario, Canada \\ N6A $5 \mathrm{C} 2$
}

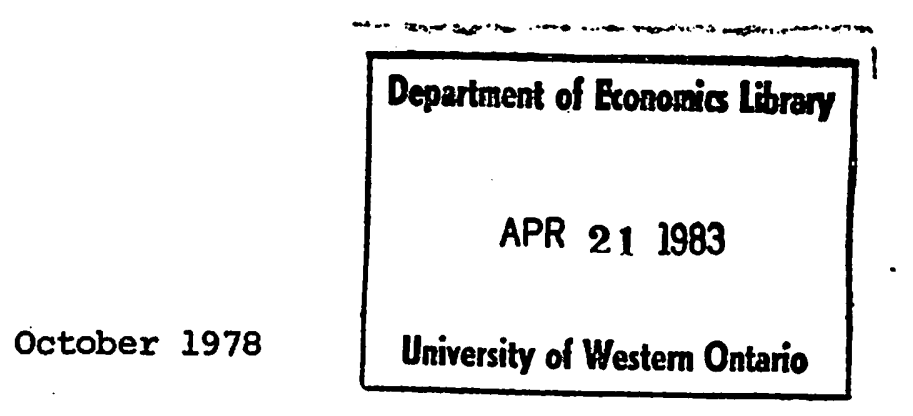

This is a revised version of a paper presented at the International Economic Association Conference on "Unemployment in Western Countries Today," Strasbourg, 28 August - 2 september 1978. I am grateful to Sue Lawler, Robin Bade and Monica Malkus for help in its preparation and to David Laidler, Serge Kolm and many participants in the IEA Conference for comments on an earlier draft. 
This paper has four objectives. First it seeks to review the facts about unemployment and inflation with an emphasis on putting recent experience into a longer-term perspective. Additionally, a review of the facts, although in themselves well-known, provides an accessible statement of those features of the world which, as a minimum condition, any acceptable theory must be able to explain. The second objective of the paper is to review the alternative explanations for the facts about the relationship between unemployment and inflation and to critically evaluate those alternatives partly in the light of their ability to explain the observed behavior of those two variables and also in the light of their consistency with the axioms of rational behavior which have been so fruitful in most other areas of economics. The third objective is to identify and highlight puzzles and paradoxes present in the existing state of knowledge. Hopefully this will serve to put into sharp focus the ongoing research task in this area. Finally the paper analyzes, in the light of the existing state of knowledge, the key alternative policy recommendations for dealing with the twin problems of unemployment and inflation.

The paper is divided into four main sections which deal with each of these matters in turn, though the bulk of the paper is concerned with the second item raised above. First however the facts will be reviewed.

\section{THE FACTS}

The recorded facts about unemployment and inflation cover a large number of countries and a relatively long time span. Ideally all the relevant timeseries and cross-section data would be reviewed in order to establish the full range of unemployment and inflation behavior experienced. However, multicountry, cross-section work in this area is hazardous and requires painstakingly 
detailed qualifications to take account of differences in measurement across countries. Further, space limitations preclude such a comprehensive account. Recognizing its limited scope, it has been decided to focus on the unemployment and inflation experience of one country, the united States, and for the time period running from 1914 to 1978. The facts about unemployment and inflation in the US for this time period are set out in Figures 1 to 7 and are summarized in Figure $8 .^{1}$

It is immediately apparent that there is no strong simple bivariate relationship between the two variables taking the period from 1914 to 1978 as a whole. However, there are some strong simple relationships within certain subperiods. The sumary Figure 8 gives a vivid picture of the range of variability of inflation at each rate of unemployment (grouped in percent point ranges) over this sample period. It also however shows clearly one futher matter of some importance, namely, the fact that the inflation-unemployment experience since 1974 is wholly outside the range of prior experience within this sample.

The central policy questions are: why are we now experiencing a new extreme of unemployment and inflation and more importantly, what can be done to return to a more agreeable state of affairs? However, we cannot confidently answer these questions until we have a satisfactory explanation for all the facts. That is, the turbulent 20 s and 30 s as well as the more placid 50 s and early 60s. This will be kept centrally in mind when examining and evaluating alternative theoretical explanations. The facts will be repeatedly turned to and the question asked: how does this particular hypothesis cope with the facts? However, conformity with the facts about inflation and unemployment is not the only, nor even the most important, criterion for an

$1_{\text {The data are listed in Appendix } 1 .}$ 

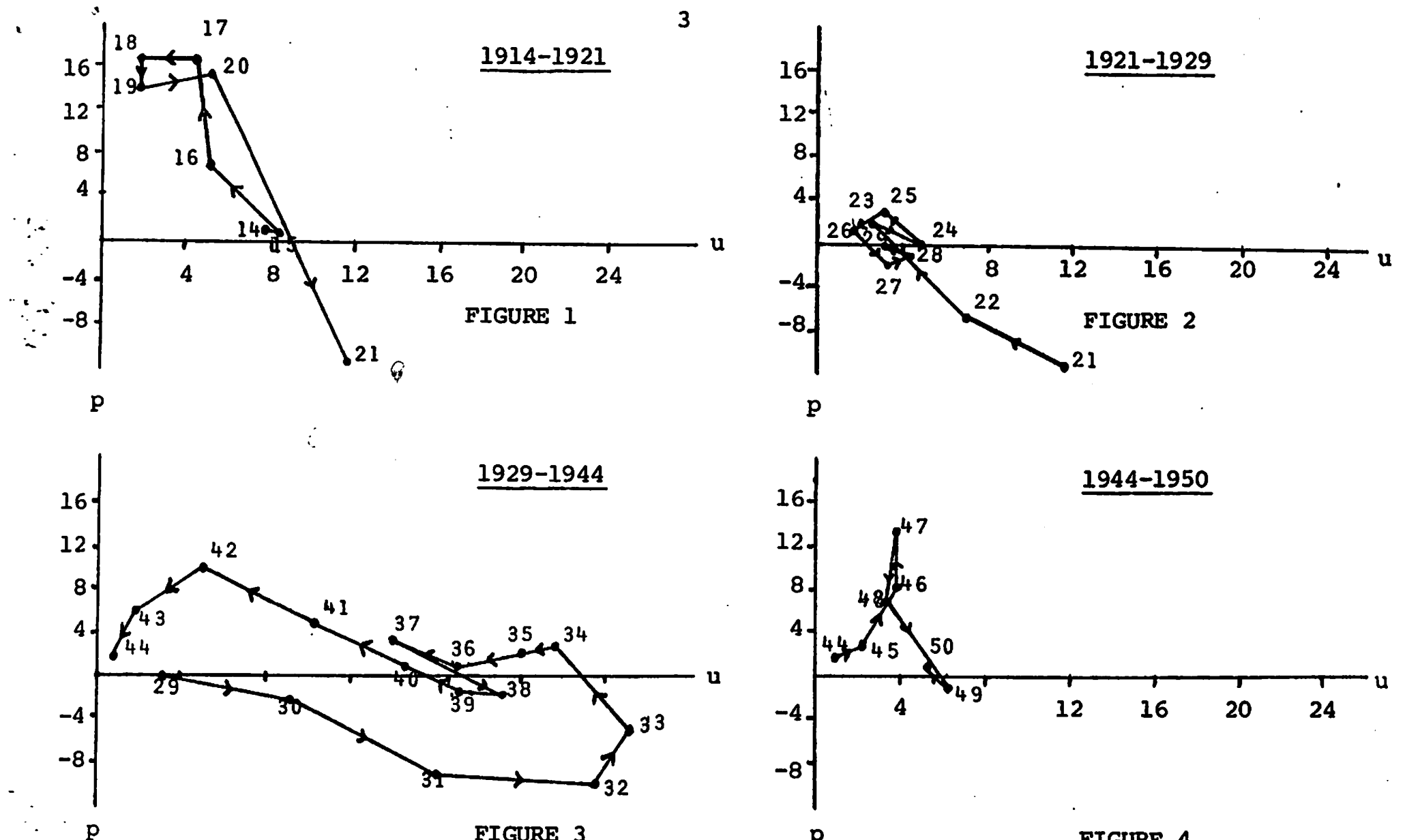

FIGURE 3
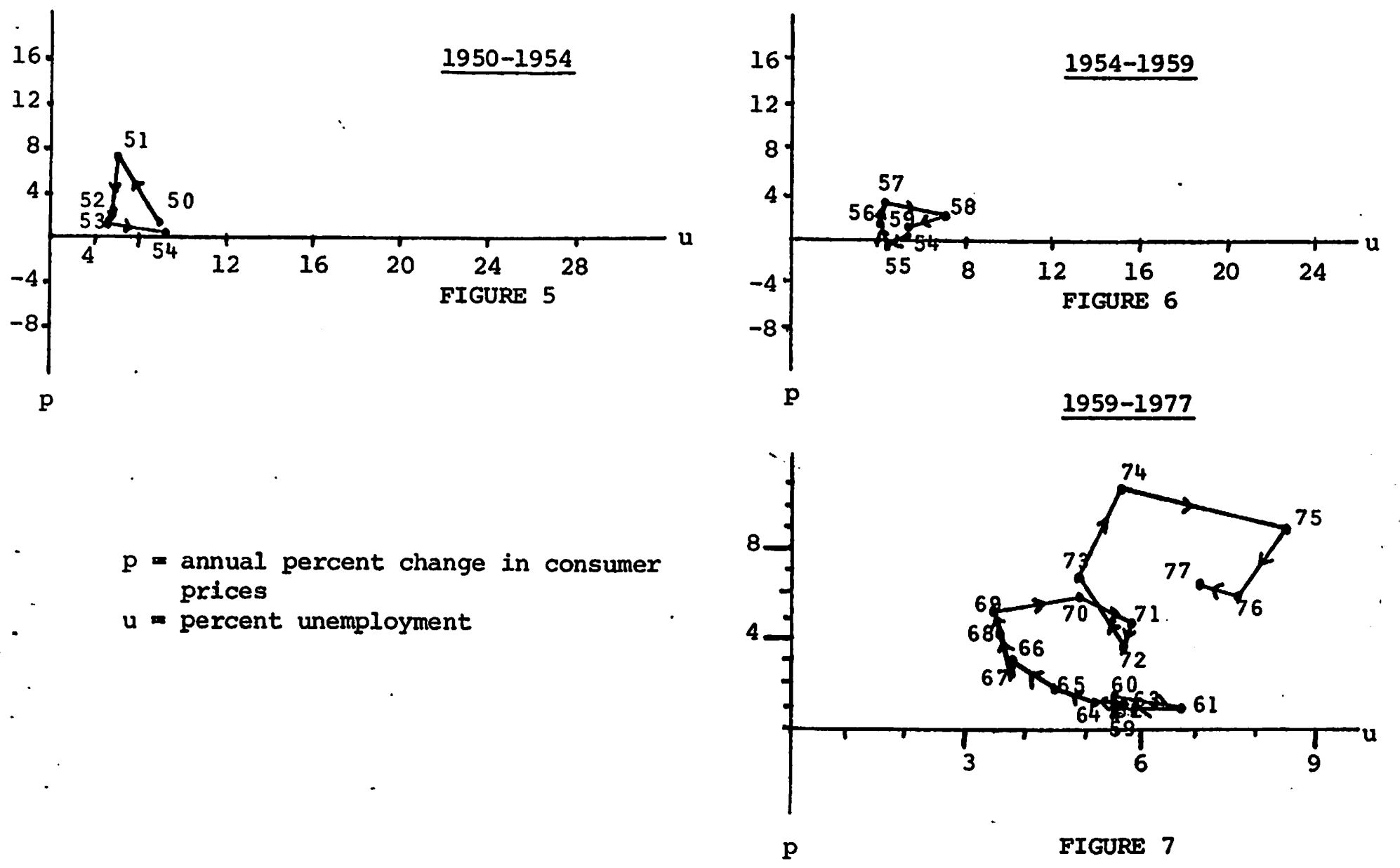
acceptable explanation of those facts. There is a broad and increasing range of facts about economic behavior which are well explained by hypotheses derived from axioms of rational maximizing behavior. It is highly desirable that these same axioms be at the foundation of our theory of the relation between inflation and unemployment. Any theory which purports to explain the behavior of these variables and does that at the expense of assuming that people either are stupid and repeatedly fail to use information that is available to them or repeatedly fail to make mutually advantageous trades must be rejected as being inconsistent with the rest of economics and as having anything to say about the world in which we actually live and therefore as having any relevance for policy.

The key alternative theories will now be examined and evaluated in the light of these two criteria.

II. THEORIES

In reviewing the alternative theories of unemployment and inflation an oversimplification will be made in the interests of streamlining the discussion. No distinction will be made between prices and wages so that real wages will be treated as if they display no systematic cyclical variability. This is not a bad stylization of reality. Further, no distinction will be made between output and unemployment as measures of the level of real economic activity. Although there is a time lag of unemployment behind output, we will proceed as if there is a rigid link between these two variables. Thus inflation, although generally taken to mean the rate of change of final prices, could equally mean the rate of change of money wages. (These two variables would of course have a different average reflecting productivity growth.) 
Theories about the relationship between unemployment and inflation date back at least to the time of David Hume (1741), who gave a clear account of a possible transmission process whereby a change in the quantity of money gave rise first to a change in the level of output and employment and subsequently to a change in wages and prices. The relationship between these two variables was first explored empirically by Irving Fisher (1926) and subsequently by A. J. Brown (1955) and Phillips (1958) whose name the supposed inverse relation between the two variables bears. Following Phillips' work, empirical evaluations of the Phillips curve (not all of them sympathetic to the approach) have mushroomed and have been surveyed by Laidler and Parkin (1975). There has also been an outpouring of theoretical work seeking to explain the facts, surveyed again by Laidler and Parkin (1975) and also by Robert J. Gordon (1977) and Anthony Santomero and John Seater (1978). This review seeks to complement and update these earlier surveys. However, it is useful to begin with the earliest postwar attempt to provide a theory of the "Phillips curve" by Richard Lipsey (1960). Even though this contribution clearly predates modern theoretical constructions, it nevertheless provides a useful basis for sharpening up the questions which have been the central concern in more recent developments.

\section{Lipsey's Theory of the Phillips Curve}

Lipsey's theory of the Phillips curve consists of two ad hoc behavioral propositions and one identity. The behavioral propositions are that the rate of inflation, $\Delta \mathrm{p}$, is proportional to proportionate excess demand $x$; i.e..

$$
\Delta \mathrm{p}=\alpha \mathbf{x}
$$

and that changes in the unemployment rate, $\Delta u$, depend positively on quits which take place at a constant rate $\beta$ and negatively on hirings which are 
proportional to unemployment, $u$ (the number of people looking for jobs) and vacancies, $v$ (the number of jobs available), i.e.,

$$
\Delta \mathbf{u}=B-\gamma \mathbf{u v}
$$

An identity defines excess demand in terms of vacancies and unemployment as

$$
\mathbf{x}=\mathbf{v}-\mathbf{u}
$$

Using the second equation to eliminate vacancies from the third and then eliminating excess demand from the first, gives Lipsey's theory of the Phillips curve as

$$
\Delta p=\frac{\alpha \beta u^{-1}}{\gamma}-\alpha u-\frac{\alpha}{\gamma} \frac{\Delta u}{u}
$$

Thus these assumptions yield the prediction that there will be an inverse relation between inflation and unemployment when unemployment is steady (when $\Delta \mathbf{u}=0$ ) and that, as unemployment changes, so the rate of inflation will be higher (lower) the faster unemployment is falling (rising). There will be a unique unemployment rate at which the rate of inflation is zero and that is given by

$$
u^{*}=\sqrt{B / \gamma}
$$

This zero-inflation unemployment rate depends positively on the quit rate (B) and negatively on the hiring rate paramter $(\gamma)$ but is independent of the price reaction function parameter $(\alpha) .^{2}$

How does Lipsey's model square with the facts? Its prediction of a generally negative correlation between inflation and unemployment seems to

2 This representation of Lipsey's model is based on that contained in footnote 32 of lipsey (1960). Everything that is presented here is to be found in that footnote although Lipsey himself did not draw out the full implications of his model, in particular its predictions of a counter-clockwise loop. Instead, Lipsey went on to develop an elaborate theory of the loops based on the aggregation of micro Phillips curves and the hypothesis that the degree of dispersion across individual labor markets was systematically related to the business cycle. Subsequent empirical work has shown that explanation for the loops to be non-viable. (See, in particular, Archibald (1969).) 
be broadly in line with the long-run average facts. Its prediction of anticlockwise loops in inflation-unemployment space appears to be consistent with the evidence for the period from 1929 to 1944 and from 1950 to 1954

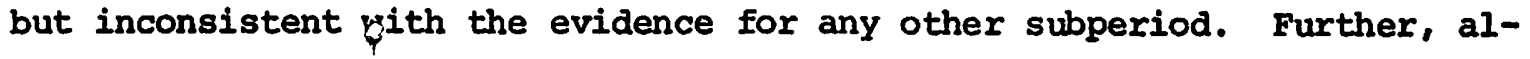
though it is superficially consistent with the 1929 to 1944 experience, the sheer size of the loop and the large movement in inflation with virtually zero movement in the unemployment rate between 1932 and 1934 as well as between 1942 and 1944 constitute a considerable problem as does the departure from the pure counter-clockwise loop as the US economy went into the 1938 recession. Further, in terms of this theory, the shifts in the zero-inflation unemployment rate as well as in the slope of the relationship between the two variables can only be "explained" by arbitrary shifts either in the reaction of prices to excess demand $(\alpha)$, the quit rate $(\beta)$ or the hiring propensity $(\gamma)$. There are enough parameters to be able to cope with the facts but, to explain the facts in terms of arbitrary changes in parameters seems hardly satisfactory.

There is a more important set of criticisms of the Lipsey hypothesis, however, arising from a consideration of individual economic behavior. First, exactly whose behavior is equation (1) supposed to describe? Is it the behavior of suppliers or demanders or some kind of reduced-form representation of what "the market" does with no individual behavior being described by the equation? This question needs an answer for two reasons; first, if $\alpha$ is a variable, it is necessary to establish the factors upon which its value depends so that variations in it may be predicted and incorporated into a fuller theoretical analysis: further, it is necessary to verify that no other variables belong in the equation and that the rate of price change responds to excess demand and only to excess demand (or vice versa, i.e., that excess demand responds 
only to price change and to no other variables). Second, and of crucial importance, the Lipsey theory provides no explicit guidance as to what determines the quantity of unemployment (or employment). The proposition usually employed in economic analysis, that demand equals supply, provides a ready method for determining the quantity. However in that case there would be no excess demand and therefore no price change according to equation (1). The alternative of allowing demand and supply to be unequal raises two problems. First, how is the quantity determined and second, how do economic agents behave in a situation in which thy are off their demand and/or supply curves? Iipsey's own (implicit) "explanation" is hardly satisfactory. It virtually overthrows the whole of the conventional supply and demand apparatus and makes mechanical assumptions about flow excess demand behavior which have no choice or price theoretic content. Indeed, the question posed concerning the first equation has equal force concerning the second. Whose behavior is described by the proposition that the unemployment rate changes negatively with respect to both the unemployment and vacancy rate? Are the decisions being made on the demand side or the supply side or in some weighted average way on both?

It is these questions arising from the lack of a satisfactory choice and price theoretic basis for the Phillips curve that gave rise to the vast amount of theoretical work that has been undertaken in recent years. However, there has. not been a single theoretical development which has found universal acceptability. Instead, there have been two broad developments, one which may be characterized as the disequilibrịum approach and the alternative equilibrium approach. The equilibrium approach itself has had two major branches, one which characterizes aggregate behavior as the outcome of a continuous auction in all markets (including labor) and one which places 
primary emphasis on the implicit contractual nature of transactions in the face of costly information and uncertainty. These modern developments are now reviewed in turn.

\section{Disequilibrium Models}

\section{(a) Phelps' Price-setting Story}

Within the spirit of the disequilibrium models, Edmund Phelps (1967) offered a "story" which sought to rationalize, although with an important modification having far-reaching implications, the basic price adjustment equation (equation (1)) above. For Phelps, equation (1) explicitly describes the behavior of firms who set prices with the objective of maximizing present value. To achieve this, they change their prices by the amount which on the average they expect other firms will change theirs plus (or minus) an amount to allow for any reduction (or increase) in market share which they seek to

achieve. ${ }^{3}$ Aggregating over all firms produces an equation similar to (1) but with an important additional variable; the expected rate of inflation $\left(\Delta p^{e}\right)$. That is,

$$
\Delta p=\Delta p^{e}+\alpha x
$$

This represents a considerable improvement over equation (1) for, by starting with a consideration of individual price setters' behavior, rather than an ad hoc price adjustment rule, it avoids the now widely acknowledged error of building money illusion into the price adjustment process. Inflation is no longer necessarily zero when excess demand is zero and any rate of inflation that is fully expected can be associated with equilibrium.

3 Phelps telis the story in terms of wage setting and the labor market and that presented here is simply a translation into the equivalent price setting story in goods markets. 
Phelps develops a generalization of Lipsey's second equation and derives the prediction that inflation will deviate from its expected rate by an amount that is greater the smaller is the unemployment rate and the faster the unemployment rate is falling, i.e.,

$$
\begin{aligned}
& \Delta p-\Delta p^{e}=f(u, \Delta u) \\
& (-),(-)
\end{aligned}
$$

This model is given empirical content with the additional hypothesis (Cagan (1956)) that expectations are formed adaptively, i.e.,

$$
\Delta p^{e}-\Delta p_{-1}^{e}=\lambda\left(\Delta p_{-1}-\Delta p_{-1}^{e}\right)
$$

A key implication of the pair of hypotheses embodied in (7) and (8) for the behavior of inflation and unemployment is that there will be a unique unemployment rate $u^{*}$ given by $f\left(u^{*}, 0\right)=0$, at which any constant rate of infaltion is possible. At constant unemployment rates below $u^{*}$ the actual inflation rate will exceed the expected rate and, via proposition (8), will cause expected inflation to rise. As a result, the actual inflation rate will also rise. Conversely, at constant unemployment rates above $u^{*}$, actual inflation will be less than expected inflation thereby reducing both expected and actual inflation. If there is a cycle in aggregate demand, complex loop patterns which may be clockwise or counter-clockwise will be generated in inflation-unemployment space. However, if the derivative of' $f($ ) with respect to $\Delta \mathrm{u}$ is small (and the empirical evidence points strongly to that being so), there will be a domination of clockwise loops. ${ }^{4}$ over the long run there will be no systematic tendency for inflation to be correlated with unemployment. It will never be possible to observe directly a short-run inverse relation (short-run Phillips curve) since any change in unemployment which would lead to a movement along a short-run Phillips curve would, at the same time, change

${ }^{4}$ See Grossman (1974) for a neat and explicit demonstration of the 10op patterns which this model generates. 
the actual and expected rate of inflation thereby shifting the short-run curve. Thus, all movements in inflation-unemployment space would represent a mixture of shifts of and movements along short-run Phillips curves.

In terms of its capacity to fit the broad stylized facts of Section $I$, this modification hardly fares any better than Lipsey's model. As already noted, from 1914 to 1929 there are virtually no discernible loops of any kind despite sizable movements of both variables. From 1929 to 1944 the loops go in the opposite direction to the clockwise pattern which this adaptive expectations augmented Phillips curve predict will dominate. It is the period 1954 to 1959 and again from 1959 to 1964 that this model works at its best. However, it cannot cope with the later years unless some arbitrary parameter shifts which have moved the natural unemployment rate are invoked. Furthermore, the problems posed above concerning Lipsey's model remain. The essential contribution of Phelps' analysis is to remove money illusion from an otherwise largely ad hoc price adjustment equation. Also the explicit analysis of the determination of quantities in the face of unequal demand and supply and a choice theoretic analysis of the interaction of price and quanti.ty determination is absent. ${ }^{5}$ This last problem however has been addressed by the mainstream branch of disequilibrium theorists. It is to a review of that work that attention is now turned.

\section{(b) Clower-Barro-Grossman-Malinvaud Disequilibrium} Quantity Determination

The pioneering work on quantity determination when supply and demand are unequal was done by Robert Clower (1965) and has been most thoroughly

5 Though Phelps and Winter (1970) do deal with this problem at the level of the individual firm. 
developed by Robert Barro and Herschel Grossman (1971, 1976) and recently taken up by Edmond Malinvaud (1977). The basis of all these models is that for some reason that is not specified in the analysis, money prices (and wages) are given and are not necessarily equal to their market-clearing values. In this event, "notional" demands and supplies are unequal, and plans which are the outcome of utility and profit-maximizing calculations with market-clearing, cannot be implemented. When agents attempt to implement their plans they are frustrated. In effect, this imposes an additional set of tighter constraints upon individual maximizing behavior and changes the form of excess demand functions to include quantity as well as price variables. (In terms of Keynesian analysis, the attraction of this approach is that it rationalizes the role of income as an argument in the consumption function and the change in income (the acceleration principle) as an argument in the investment function.) of course, in the face of a difference between aggregate supply and aggregate demand, there is an infinity of ways in which that aggregate may be allocated to individuals. The existing stock of disequilibrium models makes the simplest and crudest ad hoc assumptions about this allocation process. Typically, each individual agent bears a fixed share of the aggregate discrepancy between demand and supply. Agents are not allowed to use economic resources to shift the burden of uncleared markets away from themselves and on to others by any device (and of course by the initial assumption of the model, least of all by changing the price offer at which they are willing to trade).

These models do provide an account of how quantities might be determined in the face of a discrepancy between demand and supply. Further, they provide an account of the movements of output, employment and real wages in response to an aggregative shock which are broadly in line with the stylized 
facts. However they pay a high price for their success. First they assume an ad hoc price adjustment process which is not allowed to interact in any explicit way with the maximizing decisions of individual agents. Prices are parametric for all decisions. Second, they assume an entirely arbitrary rationing procedure with no economic analysis of why the consequences of uncleared markets fall on the particular individuals that they do. These two problems can be seen as really being one: put more simply, these models offer no explanation as to why rational economic agents fail to engage in what appear to be mutually advantageous trades. Of course, it may be that there is some lack of information which "explains" this failure. However, those models offer no guidance as to what that information gap is, why it arises nor any assurance that its effects are appropriately modeled with fixed prices and arbitrary quantity rationing.

Whilst, from the middle 1960s to around 1970, this approach to modeling the aggregate economy looked extremely promising, that promise now seems largely to have faded. It is too early to reject the approach out of hand and it still has many adherents and indeed continues to attract imaginative scholarly contributions. It is, however, hard to see how the approach can satisfactorily meet the objections stated above without in effect taking on board the major insights and analytical apparatus of the alternative equilibrium models which place primary emphasis on the role of information in generating output movements. It is to this class of models that attention is now turned.

\section{Equilibrium Nodels}

(a) Continuous Spot Auctions

Equilibrium models of economic fluctuations have a long tradition going back at least to Irving Fisher (1911). The modern treatment of equilibrium 
models, foreshadowed in Lucas and Rapping (1969) and Mortensen (1969), have been given their clearest statement in Lucas (1973) and have featured in much recent work especially by Thomas Sargent (1973) and. Robert Barro (1977a).6 The essence of the approach is that the price level (or inflation rate) and unemployment rate are determined by the intersection of aggregate demand and aggregate supply schedules. The expectations augmented phillips curve (equation (7) above) explicitly becomes an aggregate supply function. It determines the quantity of output supplied (and labor demanded and supplied, or unemployment) as a function of the actual price level relative to the expected level. Economic agents are assumed to be rational in the sense that they respond only to relative prices but they are placed in a setting in which they cannot distinguish relative price movements from movements in the general price level. As a consequence, a change in a 'local' money price will convey some information about a change in the general price level but will not provide sufficient information with which to make an exact inference about movements in the latter variable. Therefore, a rise in a particular price (or wage) will be interpreted in part as a rise in the relative price of the. commodity (or labor service) in a particular local market. Viewed in this way, the "Phillips curve" needs to be read the opposite way around from that of Lipsey and Phelps. It is the equation that tells us how much unemployment will be generated for a given discrepancy of the actual from the expected price level. Furthermore, the underlying Lipsey and Phelps story which puts the change in the unemployment rate in the relationship will no longer apply. However, costs of adjustment on the supply side can be invoked in order to

6 The most rigorous general equilibrium development of the approach is to be found in Lucas (1973). The equilibrium approach seems also to underlie Friedman (1968) although that contribution also has much in common with Phelps (1967). 
rationalize a distributed lag of past unemployment rates in the relationship. The supply story explicitly embodies the natural rate hypothesis implying that purely nominal disturbances which are fully anticipated have no real effects. Thus the aggregate supply function of Lucas may be written as

$$
-\phi\left(u_{t}-u^{*}\right)=\Delta p_{t}-\Delta p_{t}^{e}+\varepsilon_{t}
$$

where $\varepsilon_{t}$ can be thought of as incorporating any lagged values of unemployment as well as embodying a purely random disturbance.

Now that there is an explicit story underlying this aggregate supply relation, it is possible to say more than was hitherto possible concerning the parameter $\phi$. Given the assumptions made by Lucas, the value of this parameter will depend on the ratio of the variance of the absolute price level to the variance of relative prices. In an environment in which the variance of relative prices is small, a change in a particular price will be read as indicating a change in the absolute price level and evoke a small quantitative (and therefore unemployment) response, whereas in an environment in which there is a large variance of relative prices, a change in a relative price will convey little information about the absolute price level and will be read as a change in relative prices thereby invoking a large quantitative (and unemployment) response.

The demand side of the equilibrium model is a conventional IS-LM aggregate demand function which, expressed in its unemployment form, may be written as

$$
u_{t}=\psi_{0}-\psi\left(m_{t}-p_{t}\right)+n_{t}
$$

where $\mathrm{m}$ is the $\log$ of the nominal money supply and the parameter $\psi_{0}$ embodies all other sources of shift in the aggregate demand function. Where the supply locus (equation (8)) and the demand locus (equation (9)) intersect determines the unemployment rate $u_{t}$ and the price level $p_{t}$ (and of course equivalently 
the inflation rate $\Delta p_{t}$ ) given $m_{t^{\prime}} \varepsilon_{t^{\prime}} \eta_{t}$ and $p_{t}^{e}$.

In order to maintain consistency, rational economic agents not only respond to relative prices, but also form their expectations in the most efficient way possible. Specifically, in order to form expectations they presume that all other agents are as rational as they are and that the price level will in fact be determined by equations (8) and (9). Formally their expectations are formed by taking the mathematical expectation of the price level conditional on all the information (I) available to them at that time. That is,

$$
p_{t}^{e}=E\left(p_{t} \mid I_{t}\right)
$$

Treating the money stock as having an expected value at $t$ of $\hat{m}_{t^{\prime}}$ the solution to the above model for deviations of the price level from its expected level, the unemployment rate and the expected price level is as follows

$$
\begin{aligned}
p_{t}-p_{t}^{e} & =\frac{\phi \psi}{1+\phi \psi}\left(m_{t}-\hat{m}_{t}\right)-\frac{\left(\phi n+\varepsilon_{t}\right)}{1+\phi \psi} \\
u_{t} & =u^{*}-\frac{\psi}{1+\phi \psi}\left(m_{t}-\hat{m}_{t}\right)+\frac{\left(n_{t}-\psi \phi \varepsilon_{t}\right)}{1+\psi \phi} \\
p_{t}^{e} & =m_{t}^{e}-\frac{\psi}{\psi}+\frac{1}{\psi} u^{*}
\end{aligned}
$$

Thus the price level will deviate from its expected level in proportion to deviations of the actual money stock from its expected level as well as by a random component reflecting the disturbances $\eta$ and $\varepsilon$. Similarly, unemployment will deviate from the natural rate in inverse relation to unanticipated money stock and, as a result of the disturbances $\eta$ and $\varepsilon$. Finally, the expected price level depends solely on the expected money stock as well as the aggregate demand function parameters and the natural unemployment rate. It should be noted that, although the money stock has been treated here 
as the only aggregate demand influencing variable the value of which is random, other variables entering through the parameter $\psi_{0}$ could also take on the same characteristic. By way of example, an extension which allows fiscal policy as well as rest of world variables to influence aggregate demand is presented in Parkin (1977).

To give the rational expectations equilibrium model empirical content it is necessary to specify a procedure for generating the expected values of the random variables such as the money stock. This is typically done by using a mixture of a reaction function analysis together with whatever order of ARIMA process is required to reduce the forecasting errors to a white noise process. This is the formulation which was employed by Barro (1977a) in his study of the effects of unanticipated money on unemployment.

The main predictions of this type of model evident from equations (11) and (12) are easy to summarize. First unemployment will, on the average, equal the natural rate and will be independent of the rate of inflation. Second, there is no general presumption for any particular slope to the relation between inflation and unemployment since in general, the expected . rate of inflation will not be constant and will depend on the expected change in the money stock. This means that changes in the actual rate of inflation will depend on both the expected and unexpected components of changes in the money stock whereas changes in the unemployment rate will depend only on unexpected changes in the money stock. Third, if the expected money stock (or expected change in the money stock) is constant, so that all variations in the money stock are unexpected, there will be an inverse relation between inflation and unemployment. Fourth, the slope of that relation will not necessarily be constant but will depend on the relative variances of the general price level and relative prices. If relative price changes are tightly distributed, then 
a small change in relative prices will be read as indicating a change in the general price level and will not evoke a large quantitative response implying a steep short-run Phillips curve. If that variance is large the Phillips curve will be flatter.

How does this model cope with the stylized facts presented in Section Q

I? A recent study by Robert Barro (1977a) has addressed this question in terms of an explicit econometric model. Modifying equation (8) to incorporate a distributed lag in the unemployment rate as well as to incorporate a shift arising from a change in conscription regulations, Barro finds that this model explains well the actual movements in unemployment in the United States throughout the entire sample period studied (1941-1973) and does extremely well in the postwar years. However, attempts to explain the 1930s with this model were not successful. Barro (1978) extends his earlier work to analyze the effects of unanticipated money on price movements. The results of this are "broadly favorable to the approach" (Barro (1978), p. 599) though the responses of prices to unanticipated money growth are incredibly delayed.

A more impressionistic evaluation of the model can be performed by returning to the charts in Part I and asking how it copes with the pattern of unemployment and inflation displayed there. For the period from 1914 to 1931 , there appears to be a well-defined inverse relation between inflation and unemployment but one, the slope of which is becoming flatter. This would seem to suggest that the expected rate of money supply growth through that period was constant implying a constant expected rate of inflation so that actual changes in the money stock relative to that expected money stock growth rate were giving rise to the tracing out of a short-run Phillips cruve. The flattening of the curve through the period would arise if the variance of relative prices was increasing relative to the variance of the absolute price 
level. A key test of the model would involve establishing whether or not that was in fact so. Casual evidence suggests it possible since this was a period of great turbulence in the world economy. However, casual impressions are no subtitute for hard empirical evidence. That the expected money stock growth rate might have been relatively stable through this period is at least in line with the facts about the then-operating monetary system based on a gold standard mechanism which provided an anchor for the money supply growth rate.

. In 1934 the US dollar was devalued against gold. This may be presumed to have substantially increased the expected rate of growth of the money stock and expected rate of inflation in the ensuing few years as a reaction to the increased dollar value of gold reserves inside the Federal Reserve system. Thus, the sharp rise in the inflation rate in 1934, while unemployment was almost $25 \%$ of the labor force, might be attributed to a rise in the expected rate of inflation arising from this revaluation of gold. As this process was going on, an unexpected change in reserve requirements led to a sharp unexpected contraction of the money stock in $1937 / 38$ thereby generating the contraction of 1938. The strong recovery from that recession is seen as being associated with an initially unexpected increase in monetary growth which, by $1943 / 44$, was followed by substantial reduction in inflationary expectations perhaps resulting from wartime controls.

The early postwar years are extremely easy to explain in the equilibrium rational expectations model and it is this period through which Barro's model tracks extremely closely. The relatively stable inflationary expectations (and money supply growth rate expectations) through the early postwar years and right up to the end of the 1960s is to be seen largely as arising from the nature of the international monetary system based on fixed exchange rates and 
a fixed dollar price of gold. This provided a solid anchor for the us monetary system and for long-term money supply growth rate expectations and, with actual money supply growth rates in the 50s and up to 1967 staying between zero and 48, fairly stable money supply growth rate and inflationary expectations were generated. The stronger money supply growth rates $(48$ to 78$)$ in the late 1960s and in the 1970s, together with the abandonment of the gold exchange standard in 1972, meant that money supply growth expectations no longer had a firm anchor and, in the current environment, expectations have to be formed on the basis of an evaluation of an ill-understood political process. Recent monetary policies have given no indication that money supply growth rates are going to be contamed at low inflationary levels and higher inflation expectations seem to have become firmly established.

The above account of the history of unemployment and inflation in the US from 1914 to 1977 told through the eyes of the equilibrium rational expectations model is of course nothing more than a story. However, it is a consistent story. It is tempting to say that it is. a story which represents a considerable improvement upon the alternatives reviewed above. However, it would be more accurate to say that it is the only consistent story that we currently have. It is not however an entirely convincing story and many problems remain. A minor problem concerns the lack of an explicit modeling of the variability of the natural rate of unemployment. The formal analyses treat the natural rate as a constant whilst in empirical work it becomes necessary to allow for shifts in the natural rate such as, for example, Barro's adjustment based on changes in draft regulations. However this is not a problem in principle. The natural rate of unemployment can readily be viewed as being determined by real factors including unemployment insurance, taxes, minimum wage laws and demographic variables without changing the essence of the approach. 
The key problem for the approach lies in the fact that those variations in unemployment induced by unexpected inflation (i.e., unexpected money supply growth an, in a more general model, unexpected changes in other demand generating variables) should be serially uncorrelated whilst any serially correlated unemployment has to be "explained" as the result of supply side adjustment lags due to some type of transactions or adjustment costs. Hall (1975) has calculated that for the postwar US only 1.78 of the variance of unemployment can be attributed to unexpected inflation whilst 98.38 of that variance must be attributed to variations in the natural rate of unemployment and therefore is left without any explanation in terms of this analysis. Lucas' own formulation of the aggregate supply function, being very closely related to his own earlier work with Leonard Rapping (Lucas and Rapping. (1969)) can rationalize a distributed lag in the unemployment rate as part of the aggregate supply response. However, in order to hold the economy in the depths of a recession of the 1930s for so long, more than adjustment costs seem to be required. If the approach is to be rescued, it must be shown that money supply growth was unexpectedly low in each of the depression years while the expected money supply growth rate began to increase after 1932. The behavior of excess reserves through the period from 1933 to 1937 seems to be compatible with such a view (see Morrison (1966) and Friedman and Schwartz (1963).)

Robert Hall (1975) has provided an ingenious alternative explanation for the persistence of unemployment to that based on adjustment costs but one which is (despite Hall's statement to the contrary), entirely within the spirit of the equilibrium auction model analysis though supplemented with an explicit search theory. Drawing on the insights of John R. Harris and Michael P. Todaro (1970). Hall develops a two-sector analysis in which there is a rigid wage government) sector and a flexible wage (private) sector. In the face of a 
reduction in aggregate demand, the wage level in the rigid wage sector refuses to respond and, as a result, although the wage in the non-rigid sector falls, the widened gap between the rigid and non-rigid sector increases the payoff to job search. As a result, workers remain unemployed for longer in the hope of finding a more highly paid rigid wage sector job. Whilst the basic analysis is correct and does indeed generate the prediction of persistence of unemployment, it is difficult to believe that any sizable fraction of the (almost) 258 of the labor force that was unemployed in 1932/33/34 was searching for a government sector job. Equally implausible is the proposition that this has applied to the American (or any other) economy during the years since 1974 .

A final problem with the class of equilibrium models reviewed in this section is the assumption that markets behave like spot auctions and clear continously. It is of course possible that this is a useful "as if" assumption. Further, the market period could be defined as having a length such that market clearing on the average over the period makes sense. However, as a matter of description, many markets for commodities and most markets for labor do not appear to resemble spot auctions. Rather they appear to involve the trading parties entering into either explicit or implicit contracts with each other embodying rules for the conduct of each party contingent on the realization of specific unforecastable (or too expensive to forecast) events.

It is to the class of models which pay explicit attention to this feature of the world which attention is now turned.

\section{(b) Implicit (and Explicit) Contracts}

The basic idea underlying the contract approach is that in a situation of uncertainty, agents can gain by trading with each other not only factors of 
2

production and goods but also risk. That is, they can enter into an implicit (or often explicit) contract for a prespecified period which sets out rules for the determination of prices and quantities and also rules for the date at which the contract will be renegotiated contingent upon future random events in such a way that any risk associated with their trading activities are shared in an efficient manner. A central problem in developing a theory of contracts is that of focusing on a relevant small number of dimensions to the contract. There are three dimensions which, as a minimum, an economic analysis needs to take account of: a price rule; a quantity rule; and a duration rule. Each rule may be fixed or may be specified as a function of variables whose realizations will be drawings from stochastic distributions. How price and quantity variables will respond to various shocks will clearly depend upon the details of the rules embodied in particular contracts. Whether these details will turn out to be of critical importance for predicting aggregate unemployment and inflation movements is not year clear on the basis of existing work. However, that work provides many insights and seems to contain some promise. It has three main strands which will be considered separately.

\section{(i) Azariadis-Bailey-Gordon: Efficient Risk Sharing}

Three related papers by Costas Azariadis (1976), Martin Neil Bailey (1974) and Donald F. Gordon (1976) develop a basic theorem on one of the minimum conditions of an efficient contract which is of potential importance in understanding one aspect of labor markets. The analyses presented by these three authors differ in detail but are identical in essentials. Only labor market contracts are analyzed although, as Grossman (1978a) has shown, the theorem readily extends to conmodity markets. Firms are assumed to be risk neutral and households risk averse. There is therefore a potential gain from 
trading risk, firms being able to extract a positive price, in the form of lower wages for bearing some of the risk of income uncertainty that households would otherwise have to bear. The specific theorem proved is that for any given employment path there exists a fixed wage which gives the households the same level of utility as a random wage would but which is associated with a higher expected profit for the firm. Thus this analysis predicts that real wages will be sticky, a prediction which seems to be entirely in line with the stylized facts. However, this analysis has nothing to say about the determination of money wages and the absolute price level. Indeed, it implies that all labor contracts will be fully indexed so that any price level uncertainty is completely removed from the contract such contracts would lead to considerable flexibility in absolute wages and prices, but of course rigidity in the real wage. Thus, although providing an underpinning for rigidity of real wages, this efficient risk sharing analysis does not provide a convincing account of why we observe nominal wage and price rigidities in the face of nominal shocks.

If, as seems likely, the problem of unemployment arises from money wage and not real wage rigidity, this model has no explanatory power.

\section{(ii) Optimal Price Setting Models}

An alternative group of models developed by Barro (1972), Bruno (1977), and Mussa (1977) go to the opposite extreme of those just considered and assume (though do not explain why) that prices are fixed in money units. There are setup costs to price adjustment so that continuous price change as implied by an auction model is always inefficient. Instead of continuous 
price adjustment, prices are set and held for a period and then changed in a step jump. The frequency of the changes and the size of the step are chosen by firms so as to maximize expected profit. This is done by balancing the cost of having a price away from the instantaneous profit-maximizing price against the cost of changing the price. The quantity rule employed in these models is that the price setter will always satisfy demand so long as the quantity demanded can be supplied at a marginal cost less than or equal to the price that has been set. However if the quantity demanded exceeds that quantity then the firm will ration and supply the quantity which maximizes its instantaneous profit.

Barro's model examines only situations in which the expected trend rate of inflation is zero and shows that as an approximation an equation like (1) above can be derived as an average over firms and over a finite time interval. The parameter $\alpha$ which relates price change to excess demand depends positively on the variance of demand or more simply on the degree of uncertainty about the firm's demand curve. Bruno and Mussa focus on the effects of a change in the anticipated trend rate of inflation on the frequency and step size and show that prices are adjusted both more frequently and with a bigger step as the expected trend rate of inflation increases.

These analyses provide an alternative rationale for the short-run Phillips curve based on price-setting (and wage-setting) firms who implicitly contract with households to supply goods (or demand labor) at a preannounced money price and to satisfy the household's demands for goods (or supplies of labor) so long as the marginal cost of production does not exceed the price (or the marginal product of labor does not fall short of the real wage) but, in that latter event to ration the household until the next price review period. 
It may appear that these models provide a choice theoretic rationalization for rationing and therefore rehabilitate the "disequilibrium" models. However it is a long step from asserting that an individual firm will ration to the prediction that rationing will be prevalent and present in the aggregate. If firms are setting their prices in the manner described by Barro, Bruno and Mussa, there will presumably at any point in time be a distribution of prices as different firms will change their prices on different dates. Therefore some firms will be rationing at a time when others are not. It is therefore not possible to make general predictions about aggregative rationing without a careful analysis of the distribution of prices and of demands. There is no problem in these models concerning the stickiness of money wages and money prices. Both are sticky because it is costly to adjust them. However, simply invoking adjustment costs without some convincing story as to why firms set their prices in money units in the first place rather than for example contingent upon the value of some general price index does not seem to be very illuminating. Furthermore it is hard to see why price adjustment costs per se would be large enough to give rise to the degree of sluggishness in money wage and price adjustments that seems to be present in the world.

\section{(iii) Indexing of Contracts}

The question as to why firms enter into (labor market) contracts denominated in money units rather than indexed contracts is analyzed by Jo Anna Gray (1976, 1978) and Stanley Fischer (1977a). The basic framework, set out most simply in Gray (1976), is one in which both real (or more accurately supply) and nominal (or more accurately demand) shocks hit the economy. Contracts are characterized by three paramters; an initial money wage, a coefficient of responsiveness of the money wage to the general price level 
(a degree of indexing), and a contract length. ${ }^{7}$ Additionally, there is a rule for the determination of the quantity of employment. This last feature of a contract was not brought out explicitly in the work of Gray and Fischer but is dealt with in some detail by Barro (1977b). The objective function considered by Gray and Fischer is the minimization of the variance of output and employment from the levels that would obtain if there was a continous auction taking place. The continuous auction does not take place (implicitly) because it would be too costly to organize and trading under contracts characterized by the parameters and rules set out above constitutes the least cost way of organizing trades. Given the assumed optimality criterion it is shown that in general it will not be optimal to fully index and the optimal degree of indexing will depend on the ratio of the variance of nominal disturbances to the variance of total disturbances (real and nominal). Only if the only source of uncertainty is nominal will it be optimal to fully index. If nominal disturbances are seen as unimportant and real disturbances dominate then it will be efficient to not index at all. This result is derived even in the absence of indexing costs. If there are costs of indexing in the form of monitoring the index and adjusting wage schedules, then indexing will not take place unless nominal disturbances are greater than some critical value. Optimal contract length is also shown to be a decreasing function of the amount of uncertainty.

These analyses are potentially of great importance for they suggest a non-trivial reason why indexing may not be prevalent and why contracts may be fixed in money units. However they are not without their problems.

${ }^{7}$ Gray (1976) and Fischer (1977a) deal only with the first two aspects of an indexed contract, whilst Gray (1978) deals with the question of optimal contract length. 
First, the objective of minimizing the variance of real output and employment relative to the values which would prevail under a continuous auction is not obviously the nelevant criterion for optimal choices by firms and households. It would be more interesting if these analyses could be couched in terms of expected profit-maximizing firms and expected utility maximizing households than in terms of a rather arbitrary minimization of employment and output variance relative to its auction value. Further, the quantity (employment) determination rule in these analyses is one which always places the firm on its demand curve. Households are assumed to be willing to work even though the marginal disutility of work exceeds the real wage and also willing to accept a situation in which the reverse inequality holds. This implies that households and firms entering into contracts of this type do so knowing that circumstances will arise in which they will have blocked trades which are mutually advantageous. Although, as Fischer (1977b) has suggested, such contracts do seem to be a feature of the actual world, it remains a mystery as to why.

The contracting literature which has just been reviewed clearly provides some insights into the question of why nominal pxices might be sticky. It also provides a potential reason why unemployment might be more persistent than would be implied by a continuous auction model even where expectations are formed using all the available information. An examination of a model embodying these features has been examined by Stanley Fischer (1977c).

The key difference between the equilibrium auction models and the contract models is in their underlying "story" about the aggregate supply side. For the auction model, costly adjustment of factor inputs puts autoregressiveness into the aggregate supply response which supplements a nonautoregressive response to unanticipated price changes. For the contract 
model, costly contract negotiation and price setting makes the current . departure of aggregate supply from its full employment level depend not only on current period unanticipated inflation but also on unanticipated inflations which occurred eaflier in the term of any existing contracts. Either way there is an autoregressive component to the aggregate supply (and unemployment) response and it is hard to see how a discriminating test between the two approaches involving aggregative data will be devised. The facts which the auction hypothesis can explain, can be explained by contracts and vice versa. The puzzles for the auction approach are equally puzzling for the contract view of the world.

But let us now turn to a more systematic consideration of the major puzzles in this area.

III. PUZZLES

Throughout the preceding section an attempt has been made to present the alternative theoretical approaches designed to explain unemployment and inflation and to check those theories both against the facts about those two variables as well as for their conformity with rational profit and utility maximizing behavior and many puzzles and problems have been noted: This section seeks to highlight the major puzzles and to suggest possible fruitful lines of research which they indicate.

The major puzzles of course are questions concerning the explanation for particular episodes. The episode of the immediate past and present is of course one of key importance. Why has the inflation and unemployment record of the last four years been so far out of line with our earlier experience? The other major awkward episode is the period following the movement into the Great Depression. The fact of the Great Depression and its depth are not mysterious. However the persistence of a high rate of unemployment through 
the middle 1930s with a sharp increase in the inflation rate constitutes a major puzzle.

As the previous section indicates, there is no overabundance of satisfactory theories. The only analysis which is capable of telling a story which approximates to the facts is that embodying rational expectations and including, on the supply side, sluggish adjustment of employment either for reasons based on the contract story or for reasons arising from costs of adjustment embedded into a Lucas-type aggregate supply curve. Neither of the available rationalizations for slow adjustments of nominal wages and prices and consequently persistence of unemployment seems readily to cope quantitatively with the persistence of the Great Depression and are even hard to square with the persistence of modern recessions such as the most recent one. A key problem then is to find a convincing rationalization for the persistence of unemployment in excess of the natural rate. Just what are the significant costs of adjustment which give rise to such slow nominal price and wage changes and thereby generate persistent depressions of employment? I suspect that the answer to this question is not going to be found solely or even mainly as a result of further theoretical innovation. On the contrary, I suspect that careful and perhaps even tedious empirical work is required. We need to know precisely what kinds of contracts explicitly and implicitly but more important implicitly characterize labor markets. Are there important differences in the implicit contracts in different types of markets and, if there are, is it the case that unemployment typically arises in markets characterized by a specific kind of contract? If so, why is it in the interests of both parties to enter into such contracts? By focusing on the distribution of contract types and the resultant distribution of employment 
and unemployment variability, we should be able to shed more light on the question of whether or not the characteristics of contracts have a crucial role to play in an analysis of the persistence of output and employment movements.

To check out the Lucas supply story further requires a careful empirical evaluation of costs of adjustment on the demand for factors--especially labor. Again cross-section evidence would seem to be of critical importance here. Are there some sectors where the cost of adjustment of labor input is particularly great and others where it is relatively low? We should observe that unemployment persists longest in those sectors of the economy where adjustment costs are greatest. Is this the case? Further, can the adjustment costs that can be objectively measured quantitatively account for the degree of observed persistence in unemployment?

However I suspect that the critical problem in explaining persistence is not going to reside in identifying precisely what the important costs of contracting and factor input adjustment are but rather in establishing how agents use information to form their expectations of the general price level (and inflation rate). Whilst the insights of rational expectations embodied in the equilibrium and contract models have revolutionalized our perceptions, our current method for empirically implementing the hypothesis of rational expectations is surely too naive and must itself be one of the major reasons why we can explain so little in terms of unexpected price changes and have to rely so much on ad hoc adjustment or contracting costs. Whilst it is a defensible scientific strategy to postulate unobservable constants such as preference functions, the use of unobservable variables such as the expected inflation rate or expected money supply growth rate makes convincing hypothesis testing and rejection virtually impossible. Whilst the 
$Q$

basic message of rational expectations, that agents make efficient use of all relevant information is surely correct, precisely what the relevant information is and precisely what efficient use means when information is costly to acquire is by no means transparent. Assuming that agents know the true model (whilst the economics profession remains ignorant) seems to be going too far. The very fact that we are puzzled by the persistence of the Great Depression and the persistence of above natural unemployment in various phases of the postwar business cycle should at least create some doubt that the average economic agent can, on the basis of an expectation of the money stock, form an expectation held with much confidence concerning the immediate future price level. Clearly what we need as a first step in the process of figuring out how expectations are formed is a set of measurements of expectations themselves. I do not see how we can duck this and at the same time retain a method of analysis in which expectations play a central role. It is probably going to be impossible to construct objective measures of expectations for any period let alone periods long past. However for the recent past and future there is no reason why measures of expectation should not be constructed based on explicit surveys. The survey technique, when used as a substitute for explanation is rightly to be rejected. However, surveys are a use ful way of generating data that need expalanation. Indeed, one of the variables of central concern in this paper--unemployment--is itself measured by survey techniques. Also, where the central matter of concern is to know what agents believe (right or wrong) then the survey approach seems entirely appropriate. The qualitative surveys of expectations about economic variables which are routinely conducted in most major countries could provide a basis for such independent expectations measurements and one method for converting such qualitative data into a quantitative series has been suggested by John Carlson and 
Michael Parkin (1975). With such independent observations of inflationary expectations it becomes possible to check out independently the properties of the aggregate supply function as well as the process whereby expectations are formed. For periods long past where direct measurement of this kind is impossible, a careful reconstruction of precisely what information was available at each relevant stage in history together with a careful documentation of what was then known (or believed) about the working of the economy might make possible the construction of a widely acceptable measure of expectations. However such will always have an element of subjectivity in it.

One matter of importance in conditioning expectations of money supply growth which was used in the above (pp. 19-21) story concerning the equilibrium models explanation of the interwar years as well as recent experience, is the nature of the monetary system (national and international) within which monetary policy is operating. The role of a fixed value for some basic commodity such as gold and the role of the exchange rate regime (and regimes in other countries) in influencing money supply growth expectations clearly needs to be explored. I suspect that when we have done a better job of measuring or developing acceptable proxies for expected money supply growth we shall find that there were in fact prolonged periods in which positive or negative prediction errors prevailed. It will be rather like looking at a time series of coin tosses and noting ten heads in a row despite the fact that each toss had an unbiased equal chance of being either heads or tails.

Although the models discussed in the previous section (with the exception of the Lipsey analysis) were all in the "natural rate" tradition and implicitly assumed a fixed natural rate of unemployment, there is of course no reason to suppose that the natural rate is in fact a constant. Analyses of the determination of the natural rate and the effects of taxes 
and unemployment insurance arrangements upon it are undoubtedly going to have an important part to play in explaining some of the movements of unemployment, and it is clear that in recent years the natural rate has increased. To some extent an analysis of what determines the natural rate is separable from the problems that are being discussed in this paper. However, there are some questions concerning the variability of inflation and the level of inflation and the natural rate of unemployment which have not been resolved and which are implicit in some of the above models. The price setting stories for example of Bruno and Mussa suggest that as the expected trend rate of inflation increases, prices will be adjusted both more frequently and in bigger steps. This implies that there will be an increase in the variance of relative prices across individual firms. In that event, along the lines of the analysis of Mortensen or Hall (referred to in the preceding section), the payoff to search activity will increase. This could therefore give rise to a positive relation between unemployment and the anticipated rate of inflation. An explicit working out of these conjectures might provide a theoretical rationalization for the apparent tendency for the relationship between unemployment and inflation to have become positive in recent years. Again however there would be a need for careful empirical work to check out whether the variance of relative prices is in any way correlated with the trend rate of inflation.

In sum, the major puzzles which confront us in this area are empirical and concern the explanation of the periods of extreme persistence of unemployment. It is these extreme observations rather than "normal" periods which provide the main testing ground for alternative theories and, whilst no doubt some theoretical innovations are going to be necessary, we are not going to resolve the puzzles by a priori reasoning. A careful formulation testing and rejection of hypotheses, implying the careful measurement 
of all the relevant variables, is the only basis on which we shall make further progress.

\section{POLICIES}

The policy questions concerning unemployment and inflation fall in two areas: (1) activism vs. passivism in monetary policy and (2) the use of incomes policies as an adjunct to an active monetary policy for containing inflation. Specifically in the current context the question may be posed as should aggregate demand be given an upward kick by (temporarily) increasing the money supply growth rate or should money supply growth be stabilized (and possibly gradually reduced) and secondly, should some kind of price and wage policy be implemented?

In the current state of knowledge it is hard to see how activism in demand management can be defended. It is true that it is possible to construct an internally consistent theoretical model based either on contracts or on inertia in a Lucas-type aggregate supply function with rational expectations in which a rise in the money stock relative to the expected money stock will increase eimployment (reduce unemployment) and without much of a rise in the inflation rate. However we do not know how to raise the actual money supply growth rate relative to the expected money supply growth rate. The process whereby monetary policy expectations are formed is ill-understood. Furthermore, active variations in money supply growth make it more difficult for agents in the future to form expectations which will not turn out to be falsified. All the existing models point to the need for a greater degree of predictability (and steadiness) in the growth rate of the money supply. This would stabilize inflationary expectations and lead to lower forecasting errors and therefore lower departures of unemployment from its natural rate. 
If there is one single active intervention needed it is clearly to change the institutional arrangements for controlling the money supply so that a lower and more steady growth rate can be delivered in the future. The details of such a change are beyond the scope of this paper but would presumably involve changes both in the technique of monetary control (moving away from interest rate targets to monetary base targets) and changing the degree of dependence of monetary policy on short-run political considerations.

A further problem pointing strongly against activism is the imprecise knowledge we have at any time (and especially at the present time) concerning the value of the natural unemployment rate. We do not know the extent to which current unemployment is induced by unanticipated inflation and the extent to which it represents "natural" i.e., real forces. Any monetary policy । strategy which targets the money stock on to an unknown natural unemployment rate is almost certain to lead to long-term inflationary problems and large gyrations in money supply growth rates.

As regards the effects of incomes policies, our theoretical knowledge of their effects both on aggregate and allocative behavior is virtually nonexistent. However a great deal of empirical work has been done attempting to measure the effects of policies of the type employed in the past and with the broad verdict that they help a little in reducing the inflation rate below what it otherwise would have been but not much. A full catalogue of their allocative and distributive consequences is not available to us. The broad verdict of the profession seems to be that incomes policies of types hitherto practised are of zero or perhaps even negative value. However advocates of incomes policies are the ultimate messengers of hope, always seeking to suggest new versions of their product which will overcome the problems with the old variety. A current fad is for a tax-based incomes policy, a policy 
which would vary the tax rate applicable to corporate profits in direct relation to the scale of wage and price change on the corporation's labor inputs and outputs. Whilst there does not appear to be a rigorous theoretical analysis of the effects of such a policy in the literature, it is easy to see how one could analyze its effects in the context of the models presented in Section II above. In the context of a price (or wage) setting model of the Barro-Bruno-Mussa variety, it is clear that such a tax based incomes policy would in effect raise the cost of price (and wage) adjustment. The predictions of those models is that in that event prices and wages would be adjusted less frequently and involve on the average more temporary rationing by firms as they approach the price review date. However there would be no change in the relation between the expected rate of inflation and actual inflation rate. The key prediction therefore from this class of model would be for a flattening of the Phillips curve and for the curve to pivot on the natural unemployment rate and expected rate of inflation. Thus, whether such a policy raised or lowered the inflation rate would depend on whether the economy was above or below the natural unemployment rate. At the natural. rate the policy would have no effect on the inflation rate but would of course have detrimental allocative effects. Below the natural rate, inflation would be lower than otherwise and above the natural rate, higher than otherwise. In terms of the Lucas aggregate supply model, the tax would have similar effects via its operation on the effective private marginal costs of producers. A careful working out of the propositions just stated in the context of these models would be a valuable contribution to the literature. It is hardly needed however to buttress the already overwhelming administrative arguments against this particular form of incomes policy.

The preceding discussion of policy towards unemployment and inflation has been entirely prescriptive and normative. That is the way we normaliy 
discuss these matters. However, we are now becoming increasingly aware that policy is made by politicians who' are themselves ordinary economic agents seeking to maximize their own utility subject to budget constraints and additional constraints imposed upon them by constitutions and costly to change institutions. If the existing theories of the determination of inflation and unemployment which explain these problems as the consequences of unexpected policies are broadly correct, then a rigorous positive analysis of the behavior of policymakers themselves is going to be essential both to the complete understanding of why inflation and unemployment fluctuate in the way that they do and to the development of a constructive and relevant discussion of how decisionmakers may be constrained so that their own maximizing choices will lead to a more satisfactory macroeconomic performance. 


\section{BIBLIOGRAPHY}

Archibald, G. C. (1969), "The Phillips Curve and the Distribution of Unemployment," American Economic Review, Papers and Proceedings, vol. $59(2), 124-134$.

Azariadis, C. (1975), "Implicit Contracts and Underemployment Equilibria," Journal of Political Economy, vol. 83, no. 6, December, 1183-1202.

Bailey, M. N. (1974), "Wages and Employment under Uncertain Demand," Review of Economic Studies, vol. 41, January.

Barro, R. J. (1972), "A Theory of Monopolistic Price Adjustment," Review of Economic Studies, vol. $39,17-28$.

(1977a), "Unanticipated Money Growth and Unemployment in the United States," American Economic Review, vol. 67, no. 2, March, $101-115$.

(1977b), "Long-Term Contracting, Sticky Prices and Monetary Policy," Journal of Monetary Economics, vol. 3, no. 3, July, 305-316. (1978), "Unanticipated Money, Output, and the Price Level in the United States," Journal of Political Economy, vol. 86, no. 4, August, 549-580. and H. I. Grossman (1971), "A General Disequilibrium Model of

Income and Employment," American Economic Review, vol. 61 (1), 82-93. (1976), Money, Employment and Inflation, New York, Cambrldge

University Press.

Brown, A. J. (1955), The Great Inflation: 1939-1951, London, Oxford University Press.

Bruno, M. (1977), "Price and Output Adjustment: Microfoundations of Macro Theory," Harvard Institute of Economic Research Discussion Paper No. 534, February.

Cagan, P. (1956), "The Monetary Dynamics of Hyperinflation," in M. Friedman (ed.). Studies in the Quantity Theory of Money, Chicago, IL, University of Chicago Press. 
Carlson, J. A. and J. M. Parkin (1975), "Inflation Expectations," Economica (NS), vol. $42(166), 123-138$.

Clower, R. W. (1965), "The Keynesian Counterrevolution: A Theoretical Appraisal," in F. H. Hahn and F. Brechling (eds.), The Theory of Interest Rates, London, Macmillan.

Fischer, S. (1977a), "Wage Indexation and Macroeconomic Stability," Journal of Monetary Economics Supplement (Carnegie-Rochester Conference Series, vol. 5), 107-147.

(1977b), "Long-Term Contracting, Sticky Prices and Monetary Policy:

A Comment," Journal of Monetary Economics, vol. 3, no. 3, July, 317-324. (1977c), "Long-Term Contracts, Rational Expectations and the Optimal Money Supply Rule," Journal of Political Economy, vol. 5, no. 5, 191-206.

Fisher, I. (1911), The Purchasing Power of Money, New York, Macmillan. (Latest edition, New York, A. M. Kelley, 1963.) (1926), "A Statistical Relation Between Unemployment and Price Changes," International Labour Review (reprinted as "I Discovered" the Phillips Curve," Journal of Political Economy, vol. 81 (2), pt. 1, March/April (1973)), 496-502.

Friedman, M. (1968), "The Role of Monetary Policy," American Economic Review, vol. 58 , no. $1,1-17$.

Friedman, M. and A. J. Schwartz (1963), A Monetary History of the United States, 1867-1960, Princeton, Princeton University Press (in NBER). Gordon, D. F. (1977), "A Neoclassical Theory of Keynesian Unemployment," Journal of Economic Inquiry, 431-459.

Gordon, R. J. (1977), "Recent Developments in the Theory of Inflation and Unemployment," Journal of Monetary Economics, vol. 2, no. 2, April, $185-220$ 
Gray, Jo Anna (1976), "Wage Indexation: A Macroeconomic Approach," Journal of Monetary Economics, vol. 2, no. 2, 221-235.

(1978), "On Indexation and Contract Length," Journal of Political Economy, vol. 86, no. 1, February, 1-18.

Grossman, H. I. (1974), "The Cyclical Pattern of Unemployment and Wage Inflation," Economica 41, November, 403-413.

(1978a), "Employment Fluctuations and the Mitigation of Risk," Brown University Discussion Paper, May.

(1978b), "Why Does Aggregate Employment Fluctuate?" Brown University Discussion Paper $6 / 78$ processed.

Hall, R. E. (1975), "The Rigidity of Wages and the Persistence of Unemployment," Brookings Papers on Economic Activity 2:1975, 301-335.

Harris, J. R. and M. P. Todaro (1970), "Migration, Unemployment and Development:

A Two-Sector Analysis," American Economic Review, vol. 60, March, 126-143.

Hume, D. (1741), "Of Money," in Essays, Oxford University Press.

Laidler, D. and M. Parkin (1975), "Inflation: A Survey," Economic Journal, December, 741-809.

Lipsey, R. G. (1960), "The Relationship Between Unemployment and the Rate of Change of Money Wage Rates in the UK, 1862-1957: A Further Analysis," Economica (NS), vol. 27 (105), 1-31.

Lucas, R. E., Jr. (1972), "Expectations and the Neutrality of Money," Journal of Economic Theory, no. 4, April, 103-124. (1973), "Some International Evidence on Output, Inflation Tradeoffs," American Economic Review, vol. 63, no. 3, 326-334. and L. A. Rapping (1969), "Real Wages, Employment and the Price Level," Journal of Political Economy 77, September, 721-754. Malinvaud, E. (1977), The Theory of Unemployment Reconsidered, Oxford, Basil Blackwell. 
Morrison, G. R. (1966), Liquidity Preferences of Commercial Banks, Chicago, University of Chicago Press.

Mortensen, D. T. (1970), "A Theory of Wage and Employment Dynamics," in E. S. Phelps. et al. (1970).

Mussa, M. (1977), "The Welfare Cost of Inflation and the Role of Money as the Unit of Account," Journal of Money, Credit and Banking, vol. IX, no. 2, May, 276-286.

Phelps, E. S. (1967), "Money Wage Dynamics and Labor Market Equilibrium," Journal of Political Economy, vol. 76 (4), pt. 2, 678-711. (Amended reprint in E. S. Phelps et al. (1970).) et al. (1970), The Microeconomic Foundations of Employment and Inflation Theory, New York, W. W. Norton and Co. and S. E. Winter, Jr. (1970), "Optimal Price Policy Under Atomistic Competition," in Phelps et al. (1970), 309-337.

Phillips, A. W. (1958), "The Relationship Between Unemployment and the Rate of Change of Money Wage Rates in the UK, 1861-1957," Economica (NS), vol. $25(100), 283-299$.

Santomero, A. M. and J. J. Seater (1978), "The Inflation-Unemployment TradeOff: A Critique of the Literature," Journal of Economic Literature, vol. XVI, no. 2, June, 499-544.

Sargent, T. J. (1973), "Rational Expectations, the Real Rate of Interest and the Natural Rate of Unemployment," Brookings Papers on Economic Activity $2: 1973,429-472$. 
APPENDIX 1

Data for the United States

\begin{tabular}{|c|c|c|}
\hline Year & $\begin{array}{l}\text { Rate of Inflation } \\
\text { \& p.a. }\end{array}$ & $\stackrel{8}{\text { Unemployment }}$ \\
\hline $\begin{array}{r}1977 \\
6 \\
5 \\
4 \\
3 \\
2 \\
1970 \\
197 \\
\end{array}$ & $\begin{array}{r}6.5 \\
5.8 \\
9.2 \\
10.9 \\
6.3 \\
3.3 \\
4.3 \\
5.9 \\
\end{array}$ & $\begin{array}{l}7.0 \\
7.9 \\
7.7 \\
8.5 \\
5.6 \\
4.9 \\
5.6 \\
4.9 \\
\end{array}$ \\
\hline $\begin{array}{r}1969 \\
8 \\
7 \\
6 \\
5 \\
4 \\
3 \\
2 \\
1 \\
1960 \\
\end{array}$ & $\begin{array}{l}5.4 \\
4.2 \\
2.6 \\
3.1 \\
1.7 \\
1.2 \\
1.2 \\
1.1 \\
1.1 \\
1.5\end{array}$ & $\begin{array}{l}3.5 \\
3.6 \\
3.8 \\
3.8 \\
4.5 \\
5.2 \\
5.7 \\
5.5 \\
6.7 \\
5.5\end{array}$ \\
\hline $\begin{array}{r}1959 \\
8 \\
7 \\
6 \\
5 \\
4 \\
3 \\
2 \\
1 \\
1950 \\
\end{array}$ & $\begin{array}{r}0.9 \\
2.7 \\
3.6 \\
1.4 \\
-0.2 \\
0.4 \\
0.8 \\
2.2 \\
7.6 \\
1.0 \\
\end{array}$ & $\begin{array}{l}5.5 \\
6.8 \\
4.3 \\
4.1 \\
4.4 \\
5.5 \\
2.9 \\
3.0 \\
3.3 \\
5.3\end{array}$ \\
\hline $\begin{array}{r}1949 \\
8 \\
7 \\
6 \\
5 \\
4 \\
3 \\
2 \\
1 \\
1940\end{array}$ & $\begin{array}{r}-1.0 \\
7.4 \\
13.4 \\
8.2 \\
2.3 \\
1.7 \\
6.0 \\
10.1 \\
4.9 \\
1.0\end{array}$ & $\begin{array}{r}5.9 \\
3.8 \\
3.9 \\
3.9 \\
1.9 \\
1.2 \\
1.9 \\
4.7 \\
9.9 \\
14.6\end{array}$ \\
\hline $\begin{array}{r}1939 \\
8 \\
7 \\
6 \\
5 \\
4 \\
3 \\
2 \\
1 \\
1930\end{array}$ & $\begin{array}{r}-1.4 \\
-1.9 \\
3.6 \\
1.0 \\
2.5 \\
3.3 \\
-5.3 \\
-10.8 \\
-9.2 \\
-2.6\end{array}$ & $\begin{array}{r}17.2 \\
19.0 \\
14.3 \\
16.9 \\
20.1 \\
21.7 \\
24.9 \\
23.6 \\
15.9 \\
8.7\end{array}$ \\
\hline
\end{tabular}


APPENDIX 1 (cont'd.)

\begin{tabular}{|r|c|c|}
\hline & Rear of Inflation & \\
Y p.a. & 8 \\
\hline 1929 & 0 & 3.2 \\
8 & -1.4 & 4.2 \\
7 & -1.9 & 3.3 \\
6 & 0.9 & 1.8 \\
5 & 2.5 & 3.2 \\
4 & 0.2 & 5.0 \\
3 & 1.8 & 2.4 \\
2 & -6.6 & 6.7 \\
1 & -11.3 & 11.7 \\
1920 & 14.7. & 5.2 \\
\hline 1919 & 13.8 & 1.4 \\
8 & 16.1 & 1.4 \\
7 & 16.1 & 4.6 \\
6 & 7.3 & 5.1 \\
5 & 1.0 & 8.5 \\
4 & 1.3 & 7.9 \\
& & \\
\hline
\end{tabular}

Sources:

1. Consumer Price Index (Annual Rate of Change)

1913-1970: Historical Statistics of the United States Colonial Times to 1970, Part I, Bicentennial Edition, US Bureau of the Census, Washington, DC, 1975, p. 210.

1971-1977: Monthly Labour Review, US Department of Labor, Bureau of Statistics, June 1978, p. 87.

2. $\&$ Unemployed ( 8 of the Civilian Labor Force)

1913-1970: Historical Statistics of the United States Colonial Times to 1970, Part I, Bicentennial Edition, US Bureau of the Census, Washington, DC, 1975, p. 135.

1971-1976: Statistical Abstract of the United States: 1977, US Bureau of the Census, Washington, DC, 1977, p. 395 .

1977: Monthly Labour Review, US Department of Labor, Bureau of Statistics, June 1978, p. 70 . 
APPENDIX 1 (cont'd.)

Unemployment and Inflation in the United States $1914-1977$

\begin{tabular}{|c|c|c|c|c|c|}
\hline Unemployment Range & $\begin{array}{c}\text { Mean } \\
\text { Unemployment }\end{array}$ & $\begin{array}{l}\text { Frequency } \\
\text { (No. of Years) }\end{array}$ & $\begin{array}{l}\text { Minimum } \\
\text { Inflation }\end{array}$ & $\begin{array}{l}\text { Maximum } \\
\text { Inflation }\end{array}$ & $\begin{array}{l}\text { Mean } \\
\text { Inflation }\end{array}$ \\
\hline $\begin{array}{l}<28 \\
=28 \text { but }<38 \\
=38 \text { but }<48 \\
=48 \text { but }<58 \\
>58 \text { but }<68 \\
=68 \text { but }<78 \\
=78 \text { but }<88 \\
=88 \text { but }<98 \\
=98\end{array}$ & $\begin{array}{r}1.6 \\
2.5 \\
3.5 \\
4.5 \\
5.4 \\
6.7 \\
7.6 \\
8.6 \\
17.5\end{array}$ & $\begin{array}{r}6 \\
.2 \\
12 \\
.9 \\
13 \\
3 \\
4 \\
3 \\
.12\end{array}$ & $\begin{array}{r}0.9 \\
1.8 \\
-1.9 \\
-1.4 \\
-1.0 \\
-6.6 \\
1.3 \\
-2.6 \\
-11.3\end{array}$ & $\begin{array}{r}16.1 \\
2.9 \\
13.4 \\
16.1 \\
14.7 \\
2.7 \\
9.2(1.3) \\
10.9(1.0) \\
4.9\end{array}$ & $\begin{array}{l}6.8 \\
2.3 \\
4.5 \\
4.4 \\
3.0 \\
-1.0 \\
5.5(1.3) \\
2.9(-0.8) \\
-2.0\end{array}$ \\
\hline
\end{tabular}

( ) excluding 1974-77 